\title{
Optimization of water reservoir volume in an urban water supply system
}

\author{
Optimización del volumen del depósito de agua en el sistema de suministro de agua urbano
}

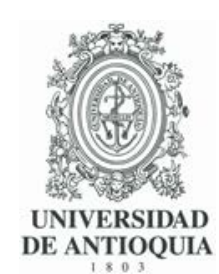

Lucija Plantak iD 1 , Bojan Durin iD 2 , Tatjana Džeba iD ${ }^{3}$, Sara Dadar iD 4
${ }^{1}$ Faculty of Geotechnical Engineering, University of Zagreb. Hallerova aleja 7, 42 000. P. C. 42000. Varaždin, Croatia.
'Department of Civil Engineering, University North. Jurja Križanića 31b, P.C. 42000 . Varaždin, Croatia.
${ }^{3}$ Faculty of Civil Engineering, University of Mostar. Matice hrvatske b.b., P. C. 88000. Mostar, Bosnia and Herzegovina.
4Water Engineering Department, Ferdowsi University of Mashhad. Azadi Square. P. C. 9177948974 . Khorasan Razavi, Iran.

\section{CITE THIS ARTICLE AS:}

L. Plantak, B. Đurin, T. Džeba and S. Dadar. "Optimization of water reservoir volume in an urban water supply system", Revista Facultad de Ingeniería Universidad de Antioquia, no. 104, pp. 178-188, Jul-Sep 2022. [Online]. Available: https :

//www.doi.org/10.17533/ udea.redin. 20210953

\section{ARTICLE INFO:}

Received: October 09, 2020 Accepted: September 04, 2021 Available online: September 06, 2021

\section{KEYWORDS:}

Water supply; pumping regime; consumption regime; functional relationships

Abastecimiento de agua; régimen de bombeo; régimen de consumo; relaciones funcionales

\begin{abstract}
In this paper, the water pumping regime, as well as the water consumption regime with regard to the required quantities and the example of water consumption, with an emphasis on changes in water volume, are examined. This aims to show the functioning of the regime of water consumption, water pumping, as well as finding functional relationships between the mentioned sizes and the volume of the water reservoir. The analysis focuses on questions such as how and in what way, changes in the onset and duration of pumping, as well as different water consumption regimes affect the size of the reservoir volume. The entire analysis in this paper was done to develop a scientifically innovative, but also applicable mathematical model, which is a contribution to the profession and a good basis for further scientific research to improve the operation of the urban water supply system.
\end{abstract}

RESUMEN: En este trabajo se examina el régimen de bombeo de agua, así como el régimen de consumo de agua con respecto a las cantidades requeridas y el ejemplo de consumo de agua de acuerdo con las pautas y normas de la profesión, con énfasis en los cambios en el volumen de agua. Este tiene como objetivo mostrar el funcionamiento del régimen de consumo de agua, bombeo de agua, así como encontrar relaciones funcionales entre los tamaños mencionados y el volumen del depósito de agua. El problema que se quiere resolver es ver cómo y de qué manera, los cambios en el inicio y duración del bombeo, así como los diferentes regímenes de consumo de agua, afectan el tamaño del volumen del embalse. Todo el análisis de este artículo se realizó con el fin de desarrollar un modelo matemático científicamente innovador, pero también aplicable, que sea una contribución a la profesión y una buena base para futuras investigaciones científicas para mejorar el funcionamiento del sistema de suministro de agua urbano.

\section{Introduction}

The Urban Water Supply System (UWSS) depends on the consumption and need for water on the one hand, as well as on the functional dependence of the capacity of pumping stations and the volume of the water reservoir. Nowadays, the pumping regime is under pressure not only because

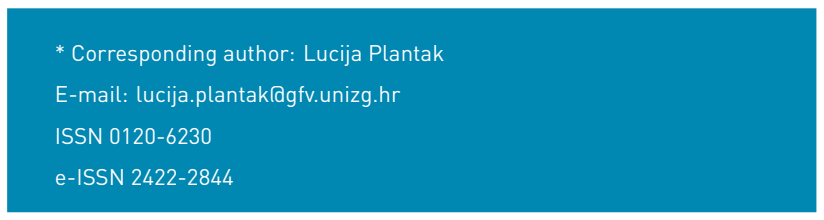

of higher consumption rates due to population growth and tourism, but also because of the negative impact of climate change. Rising air temperatures and sea levels, increased industry, harsher agricultural conditions, floods, and other hydrological phenomena are hampering the operation of the water supply systems and leading to higher water and energy consumption which leads to higher costs. For this reason, researching the above-mentioned functional dependencies and their interdependencies is important in order to gain new knowledge and improve the work of the UWSS itself. In this paper, by researching these quantities and their relationships, there is an 
intention to develop a mathematical model, which given the different water consumption regimes, will describe the relationship between pumping regimes and water reservoir volume. To develop a mathematical model, input data of parameters that are important for the work of the UWSS are needed and the insight into their functional dependencies presented in this paper will provide better optimization of the system. This would contribute to the profession and further scientific research related to this topic. By investigating interdependencies in UWSS, it will be considered if there is an increased need for water, whether the existing water reservoir can accept a certain amount of water in a certain period, without the need for its expansion. Not only will this give better optimization of such a system, but it would lead to energy conservation. One characteristic of UWSS is that water consumption goes hand in hand with energy consumption, since energy is required for water production, treatment and distribution, and wastewater collection and treatment [1]. It means that utilities buy most energy at the highest price during the day. As the water reservoir is the main functional element of the UWSS, whose purpose is to store water, ensure the necessary operating pressure and security of water supply for the population, this is the most significant, concerning all other parts of the UWSS.

Sizing of such system is done for one-day equalization on the day of maximum water consumption during the considered year, and the operational volume of the reservoir $(V)$, i.e., the volume for equalization/equalization of inflow and outflow (consumption) of water from the reservoir is obtained by graphical or numerical procedures [2]. Since the volumes of water for fire protection and incident situations are constant, in all further considerations, the necessary volumes of water storage for equalization of inflow and consumption are marked with $V$.

The entry of water into the water reservoir depends on the operation of the pumping station, which in UWSS is mostly used for pumping water from the intake to the raw water treatment plant, and from the mentioned plant to the water reservoir. In practice, the operation of water supply pumps is developed in two ways [2]:

a Continuous operation with a minimum flow equal to the average flow in the maximum day of consumption, constantly for 24 hours,

b Occasional operation of pumps during periods of low electricity prices, where the duration of operation of the pumping station is $8 \mathrm{~h}, 16 \mathrm{~h}$, or during another period.

As previously mentioned, the water inlet to the reservoir can be controlled, as it can control the operation of the pumping station, which brings water to the reservoir.
Due to the dependence of water outlets on the habits and living standards of the population, the outlet cannot be controlled. The mentioned habits and living standards of the population refer to population awareness of rational water use on which we can affect but not control. From the above, it can be concluded that the size of the operational volume of reservoir $V$ is a function of the inflow of water into the reservoir $Q i n$ and water leakage from the reservoir Qout, that is, the amount of water that the population consumes [3].

UWSS and its individual parts have been researched and processed in numerous works, studies and projects carried out on specific problems related to water and electric energy consumption. The influence of the water pumping regime and the consumption regime on the size of the reservoir volume, as well as the interdependence between the mentioned quantities, have not been processed and analyzed, which can be seen in the literature review. An analysis of the pumping regime, with respect to the duration and onset of pumping is proposed [4], in a case study in Palestine for the purpose of changing the occasional pumping regime to a continuous (permanent) one. The conversion of the existing discontinuous pumping regime to a continuous one is also analyzed in a paper [5] on a case study in Korea. That study shows the optimization of multiple water reservoirs concluding that a better-optimized pump schedule can be used for future maintenance of water reservoirs. These studies confirm that the pumping regime, in addition to the cost of pumping, also affects the duration and reliability of the water supply system.

Taking into account the assumption that pumping intensities are adjusted to hourly water needs within a day, the paper [6] found that the optimal pumping intensity in each hour is determined based on the current (net) selling price of electricity, the amount of water in the reservoir and the required amount water during the day. Pumping with increased capacity in the period of the so-called "peak", i.e., the period of maximum water and electricity consumption, is optimal according to [7] and [8], due to a more even distribution of energy consumption. Also, [7] show that with the possible increase in the power of the pumping station, it is necessary to ensure a sufficient volume of water storage, because of the storage of increased amounts of water. Pumping stations represent the highest operational costs in the water supply system, as confirmed in [2],[9] and [10]. In order to reach a general conclusion about the need for water during the intermittent and constant water supply, it is necessary to analyze or determine the water consumption regime for the poor areas, as well as for smaller and larger cities [11]. Therefore, some analysis, i.e., modeling of water pumping and consumption regimes are necessary steps 
for technical and economic analysis of each UWSS. In the paper [12], on the example of two water consumption regimes, a linear functional dependence between water tank volume and pumping duration is determined, but the mentioned analysis was made on a simplified example, for several different pumping starts and durations.

Also, [13] introduce simplification through linearization in such a way that the size of the reservoir volume during different pumping periods is determined based on the volume sizes at the beginning and end of the pumping period. The paper [14] from an engineering and mathematical point of view describes the parameters analyzed for changes in the volume of the reservoir within the genetic algorithm (Genetic algorithms - Gas), which is used to optimize the water supply network. The reservoir is a decision variable regarding the change in volume and water level in it, where again, the volume of the reservoir is crucial. Another proof of this statement is the research conducted in [15], where the reliability of the reservoir was observed with respect to its volume. It was found that numerous interruptions in the water supply from the reservoir follow the Weibull distribution, and that through the connection of the given (predicted) interruption of the duration of the water supply, the required volume of the reservoir can be determined and vice versa. The analysis of bibliographic units expressed the need and motivation for the detailed determination of functional dependencies between the regime (beginning and duration) of pumping and the volume of the reservoir.

\section{Research methodology and input data}

Theoretical assumptions of the calculation of the volume of the reservoir indicate that the longer the operation of the pumping station, the size of the required volume of the water reservoir decreases, provided that the capacity of the pumping station is constant throughout the period of operation. However, to plan the operation of reservoirs and analyze the work in case of unusual situations, it is necessary to know whether and in what way the start of operation of the pumping station has an impact on the required size of the reservoir volume. Minimizing the losses while transmission through monitoring techniques and advanced modern treatment and storage facilities will ensure the optimization [16].

Usual situations often occur in the water supply system due to the variability of water inflow and water consumption regime. For this reason, it is necessary to know what the actual relationships are between the pumping regime, the water consumption regime, and the volume of the reservoir, and what connections exist between them. The usual constraint related to the volume of the reservoir $V(t)$ at the observed moment $t$ is defined in Equation 1 [17]

$$
V(t) \leq V(t) \leq \overline{V(t)}, \forall t
$$

Where are: $V(t)$ the minimum required volume of water in the reservoir and $\overline{V(t)}$ the maximum allowable volume of water in the reservoir. Boundary conditions must also be defined in Equation 2 [17]

$$
V_{i}(1)=V_{\text {start }}, V_{i}(t+1)=V_{\text {end }}
$$

Where $V_{\text {start }}$ is the volume of water in the reservoir at the beginning of pumping and $V_{\text {end }}$ is the volume of water in the reservoir at the end of pumping. Stated quantities and their interrelationships were carried out bearing in mind the possibility of the occasional and constant inflow of water into the water reservoir. Therefore, in the case of a constant inflow of water with pumping duration through 24 hours, it will be determined whether the change in the start hour of pumping has an impact on the volume of the reservoir. On the other hand, in the case of occasional inflows, it will be determined whether and in what way changes in the start hour and duration of pumping affect the volume of the reservoir. Also, two different water consumption regimes are observed through the example of a settlement of 8970 inhabitants for maximum daily water consumption (with all losses) $Q_{\max }^{\text {daily }}=2440 \mathrm{~m}^{3} /$ day, i.e., Variant I and Variant II [12]. Required water volumes and water consumption quantities for both Variants are shown in Figure 1 and Figure 2.

This analysis seeks to determine whether there is a functional relationship between the required amount of water, the start and duration of pumping, and the volume of the reservoir, while the purpose of the observed dependencies is to try to answer one of the basic questions. The mentioned analysis refers to the dependence of the size of the required volume on the duration of pumping and the dependence of the same size on the hour of the beginning of pumping. The purpose of the presented methodology is to try to alleviate the process of planning the operation of reservoirs for the assumed regime of water consumption in the supply area and relates to the dependence of the required volume on the duration of pumping and the dependence of the same size on the start time. This analysis will help in the work of the control and management center of the water supply system during the change of possible water pumping regimes in the existing water reservoirs regarding the maximum permitted quantities (flows) of water. Also, it provides insight into the change of pressures in the water supply system, as well as the regulation of pressures with respect to the minimum and maximum allowable values. This last information about pressure changes allows avoiding the installation of pressure chambers or valves for pressure 


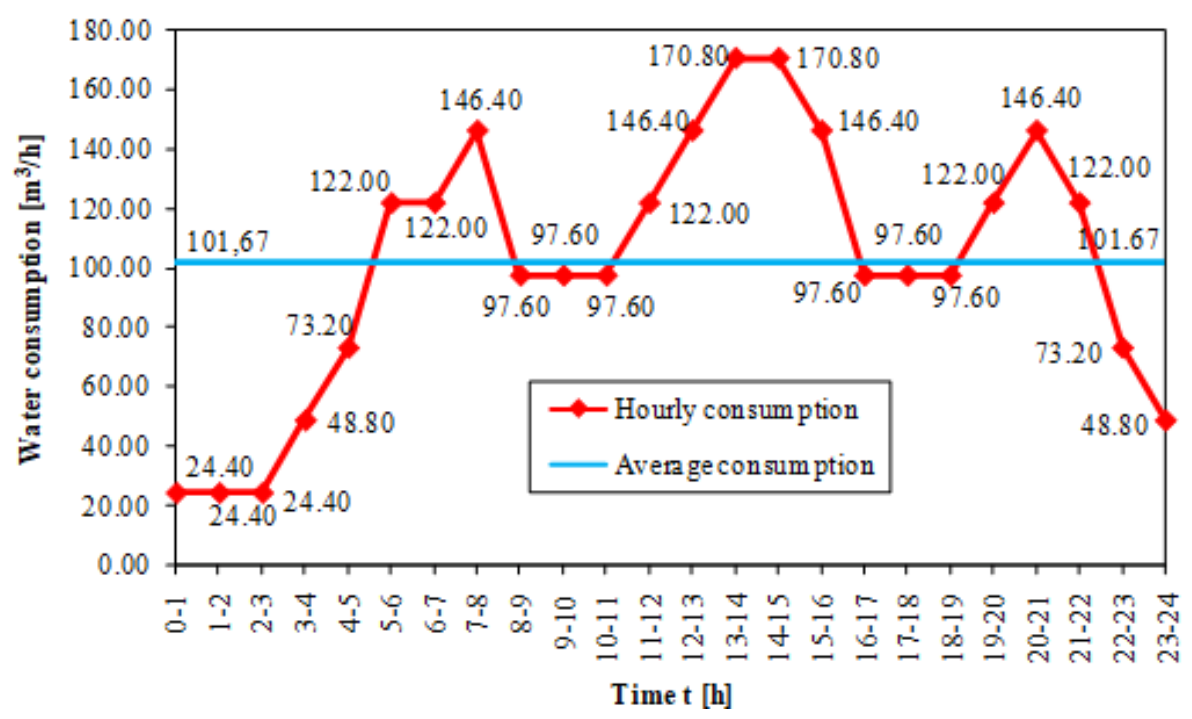

Figure 1 Overview of the daily water consumption regime for $Q_{\max }^{\text {daily }}=2440 \mathrm{~m}^{3} /$ day for Variant I [18]

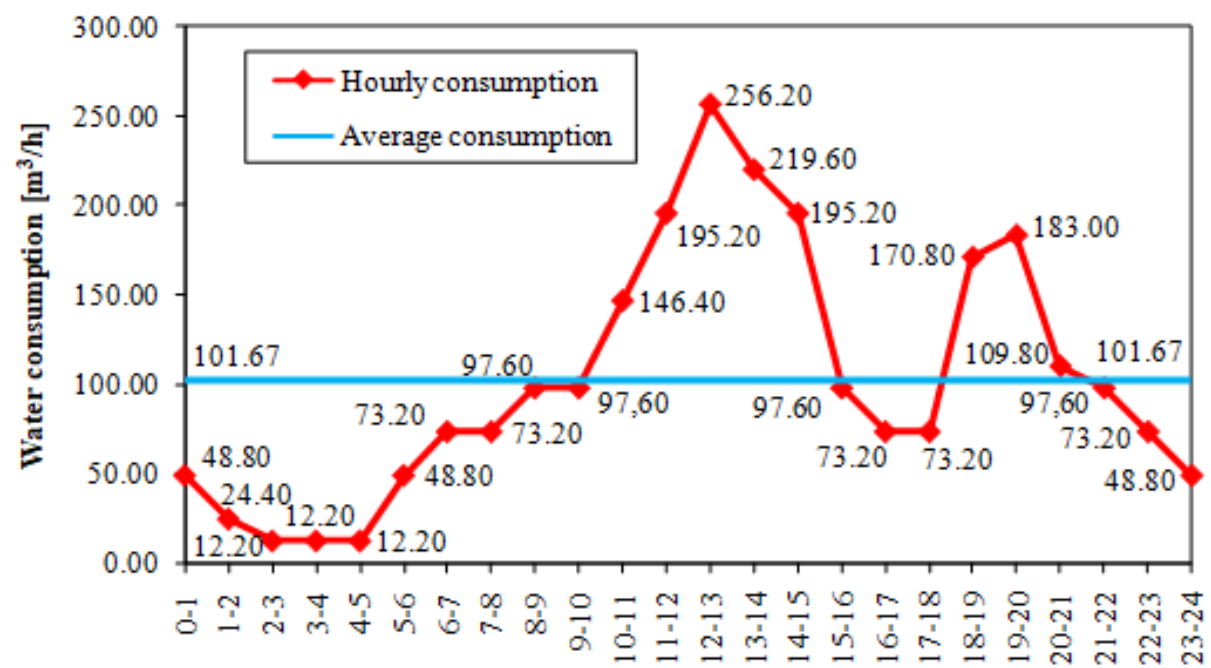

Time [h]

Figure 2 Overview of the daily water consumption regime for $Q_{\max }^{\text {daily }}=2440 \mathrm{~m}^{3} /$ day for Variant II [18]

regulation or additional programming of pumping station operation and regulation of water inlet and outlet from the water tank, which further complicates the water supply system.

\section{Obtained results and discussion}

\subsection{Influence of the beginning of the pumping period on the size of the reservoir volume, for constant water pumping within 24 hours}

In the case of constant water pumping into the reservoir for 24 hours, it will be determined whether the change in the start of pumping has an impact on the volume of the reservoir. An analysis of the influence of the beginning of the pumping period on the size of the reservoir volume for constant pumping within 24 hours was performed using the usual Ripple method [2] for both Variants, I and II. The results are shown in Figure 3.

From the obtained results, it is possible to conclude that for constant water pumping for 24 hours, the beginning of the pumping period has no influence on the size of the reservoir volume, which can be seen in Figure 3 . In other words, even if the start hour of the water pumping is changed, it does not affect the amount of water in the reservoir because the capacity of the pumping station is constant. 


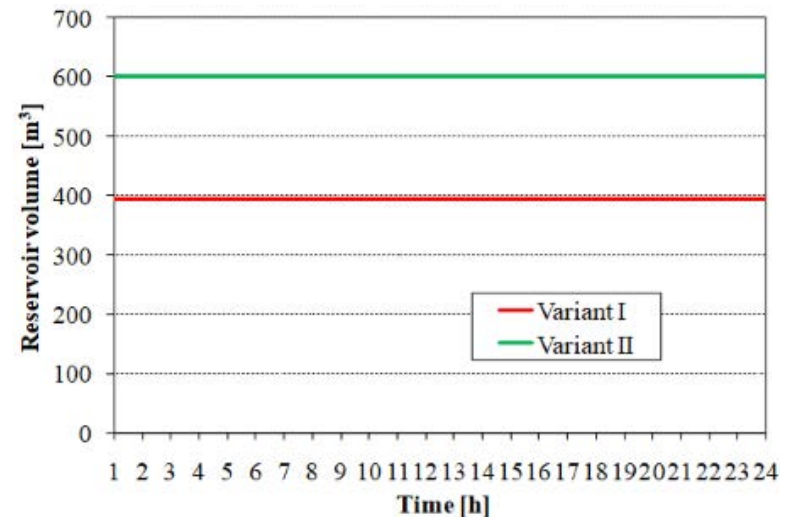

Figure 3 Reservoir volumes for Variant I and Variant II for different water pumping starts during constant water pumping for $24 \mathrm{~h}$ [12]

For both Variants, the average hourly water consumption $Q_{\text {hourly }}$ is $102 \mathrm{~m}^{3} / \mathrm{h}$, which is also the capacity of the pumping station, i.e., the inflow of water into the pumping station for the duration of pumping of 24 hours.

\subsection{Influence of the beginning of the pumping period on the size of the reservoir volume, for different durations of water pumping}

It is necessary to determine whether and in what way changes in the start of pumping and the duration of pumping affect the volume of the reservoir. The aim is to determine whether there is a functional relationship between the required amount of water, the beginning and duration of pumping, and the volume of the reservoir.

In the case of occasional water abstraction, such as different durations and different abstraction starts, reservoir volumes were calculated for the maximum daily water consumption of $Q_{\max }^{\text {daily }}=2440 \mathrm{~m}^{3} /$ day, for Variant I and Variant II, in order to find their impact on the reservoir volume. The mentioned calculations, with respect to the different beginnings and durations of pumping for Variant I are shown in Figure 4.

By examining the presented changes in volume with respect to the beginning of the pumping period and different pumping durations for Variant I, a linear part from the point indicating the beginning and duration of pumping from $6 \mathrm{AM}$ to the point indicating the beginning and duration of pumping at 6 PM was observed, Figure 5. On the linear/boundary part (from 6 AM to 6 PM), the difference in the volume of the reservoir $\Delta V=610 \mathrm{~m}^{3}$, is obtained by multiplying the value of the inflow into the reservoir in one hour $\left(101.67 \mathrm{~m}^{3} / h\right)$ with the duration of pumping from the linear part and the duration of pumping after the linear part, which is 6 hours [18]. A further study of Figures 4 and 5 shows that for a pumping duration of 20 hours and a pumping start of 3 and $4 A M$, the required reservoir volume is the smallest. The mentioned curves, which represent the dependences of the required reservoir volume on the pumping duration for different pumping start for extremes (minimum values of reservoir volume) with pumping starts at 3 and $4 \mathrm{AM}$ for Variant $\mathrm{I}$, are highlighted in Figure 6.

The same analysis was performed for the second consumption regime for Variant II. Figure 7 shows a two-dimensional view of changes in the volume of the reservoir with respect to the beginning of the pumping period and different pumping durations.

Two-dimensional representations of both Variants (Figure 4) and (Figure 7), changes in the volume of the reservoir with respect to the beginning of the pumping period and different pumping durations show that, with respect to the start and length of pumping, as well as pumping regime and input data on water consumption by population and change reservoir volumes. Different water consumption regimes (Variants I and II), but also different beginnings and durations of pumping define different interdependencies. It is also evident that the connections between these quantities are not simple at all [18].

As with Variant I, a linear part of the curve was observed here also (Figure 8), from $11 \mathrm{AM}$ to $1 \mathrm{PM}$, and the difference in the volume of the reservoir is $\Delta V=1118.37 \mathrm{~m}^{3}$. The stated volume difference is obtained by multiplying the inflow value into the water reservoir in one hour $\left(101.67 \mathrm{~m}^{3} / \mathrm{h}\right)$ with the duration of pumping from the linear part and the duration of pumping after the linear part (11 AM) [18]. The areas in Figures 5 and 8 that are bounded with black lines define the area within the reservoir volume dependence diagram on the beginnings and durations of pumping, within which the largest range is between the smallest and largest reservoir volume. By defining a bounded area, it is easier to find the possible durations as well as the beginnings of pumping given the largest range of reservoir volume change. An extreme (minimum value of the reservoir volume) was also observed for this Variant for a pumping duration of 16 hours starting at $6 \mathrm{AM}$, and the mentioned curve was isolated and shown in Figure 9.

For the stated extreme values that occur in both Variants, calculations of cumulative water inflow into the water reservoir and water consumption with pumping start at 3 $A M$ and $4 A M$, for pumping duration of 20 hours for Variant I, and at 6 AM for pumping duration of 16 hours were made for Variant II. 


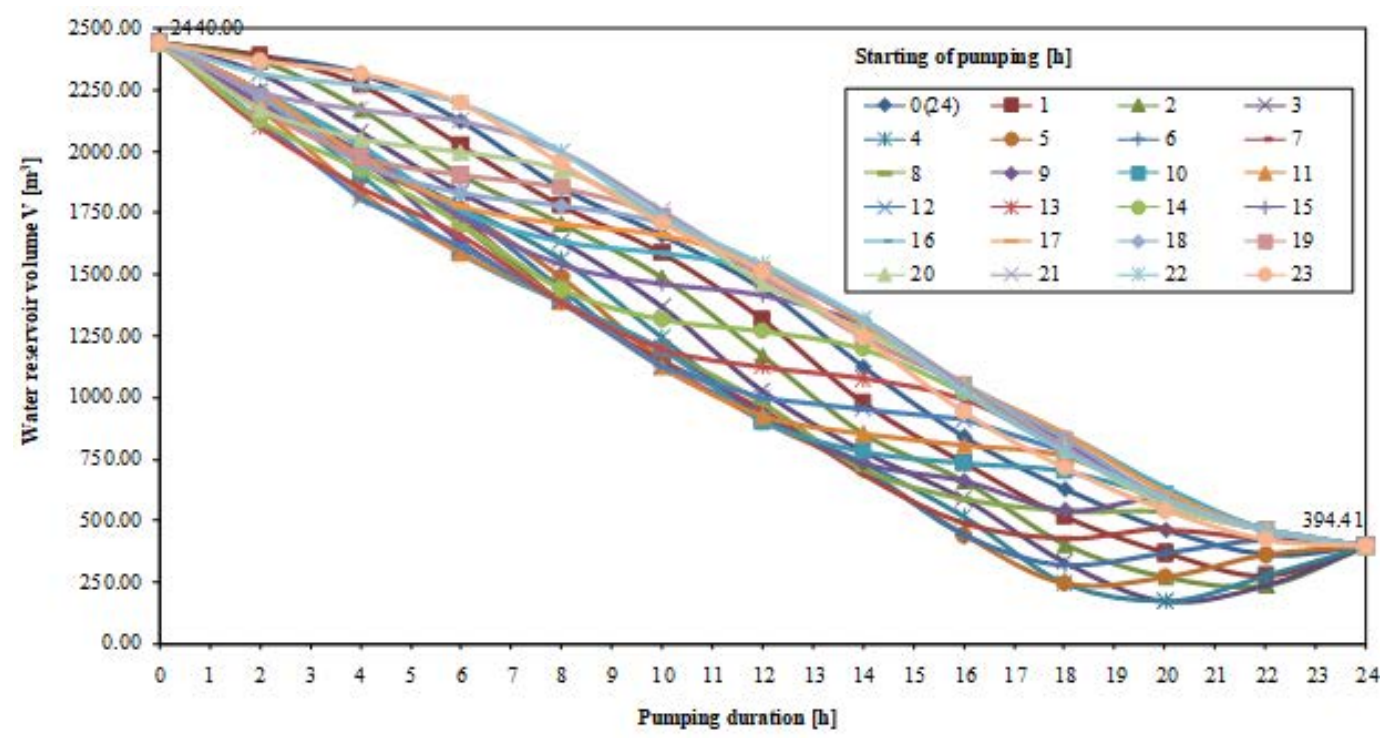

Figure 4 Changes in reservoir volume with respect to the beginning of the pumping period and different pumping durations for Variant I [18]

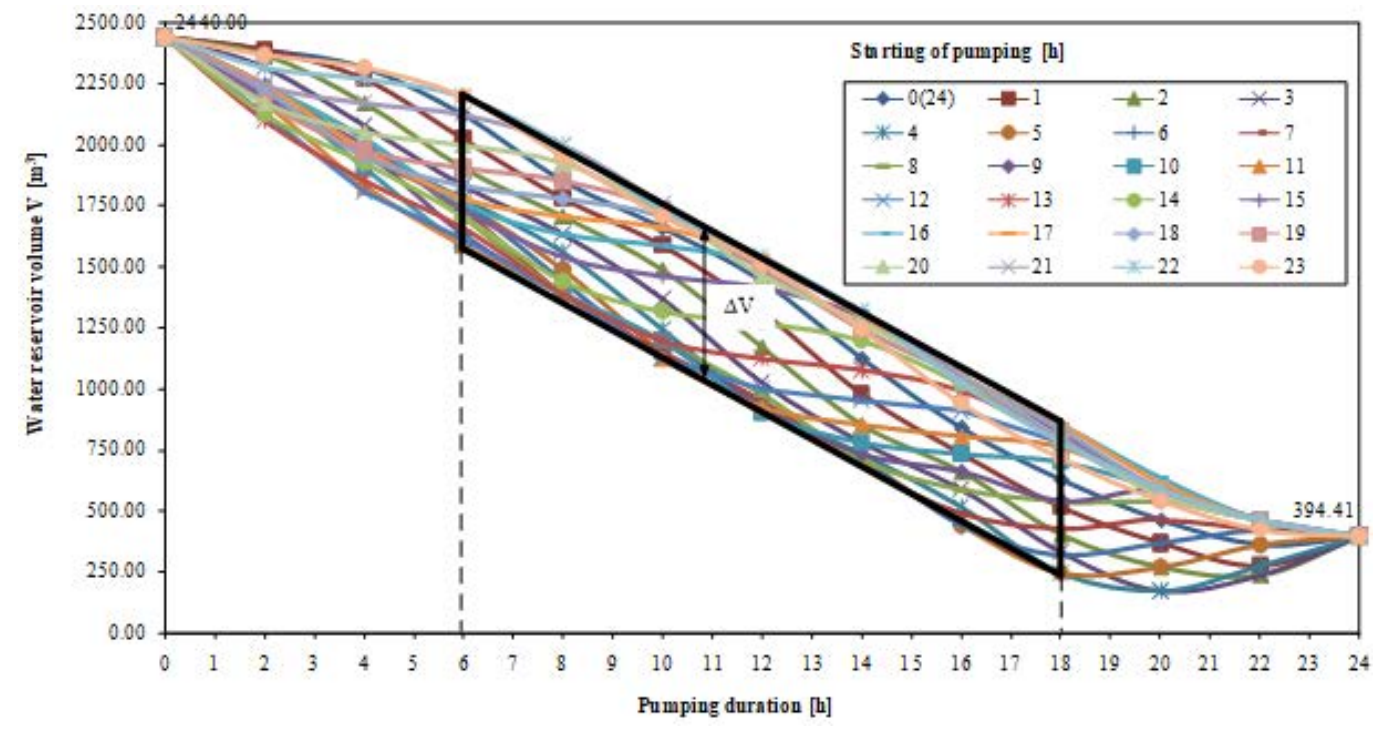

Figure 5 Dependence of the required volume of the water reservoir on the pumping duration for different pumping durations by $Q_{\text {max }}^{\text {daily }}=2440 \mathrm{~m}^{3} /$ day for Variant I

For the start of pumping at 4 AM (Figure 10), it is noticed that the point indicating the cessation of inflow, i.e., pumping of 20 hours, also indicates the point of extreme/minimum value of the volume of the reservoir, which is observed in Figure 4, where it can also be seen that with the interruption of the inflow at the 20th hour the curve is increasing, which means that the amounts of water in the reservoir are increasing. The same calculation was performed for the pumping duration of 20 hours, but with the start of pumping at 3 AM, which is shown in Figure 11.

Here, it is also confirmed that in the case when the inflow stops for the start of pumping at $3 A M$, the same point also indicates the extreme point or the lowest value of the reservoir volume observed in Figure 4, which also shows that at that time stops, the curve increases, which means that the amounts of water in the reservoir also increase.

In Variant II, the display of the cumulative inflow of water into the reservoir and water consumption by the population for the start of abstraction at $6 \mathrm{AM}$ and the duration of abstraction of 16 hours (Figure 12) also confirms, regardless of the different consumption regime, that in case the inflow stops this point also marks the extreme point. The mentioned extreme point can also be seen in Figure 7, where it can be observed that with the completion 


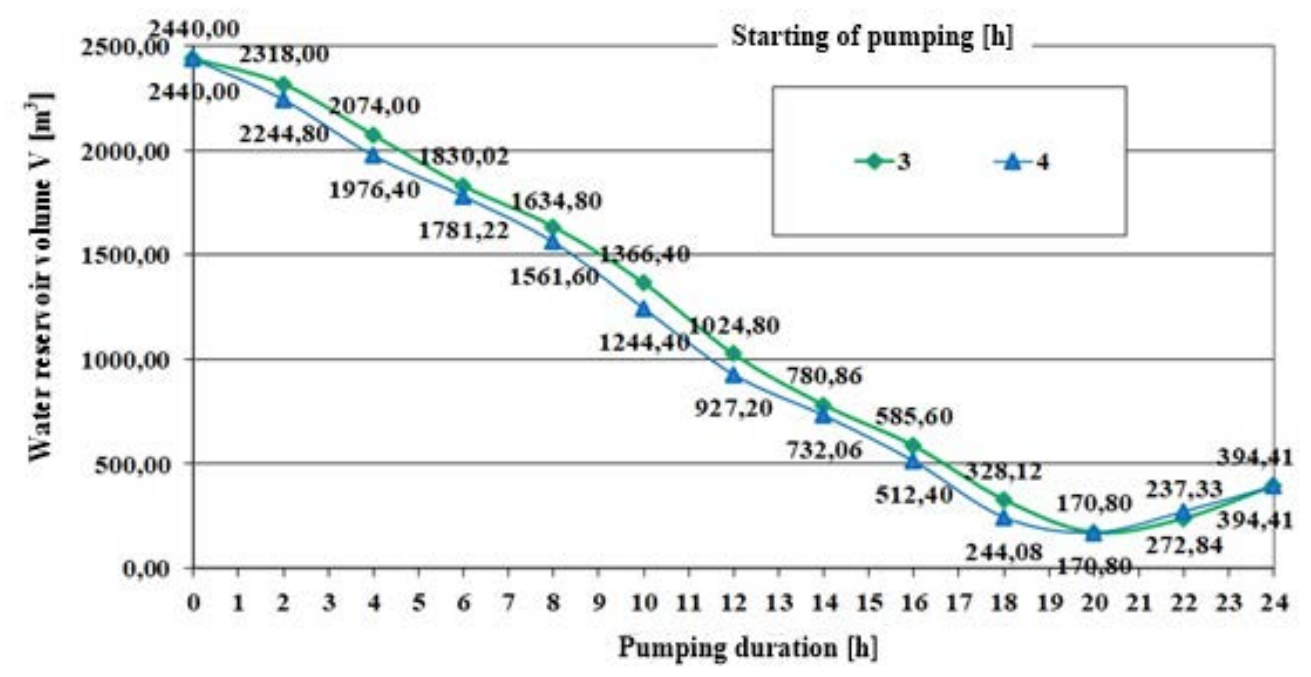

Figure 6 Dependence of the required water tank volume on the pumping duration for different pumping start for $Q_{\max }^{\text {daily }}=2440 \mathrm{~m}^{3} /$ day for extremes (minimum values of water tank volume) with pumping starts at 3 and $4 \mathrm{AM}$ for Variant I

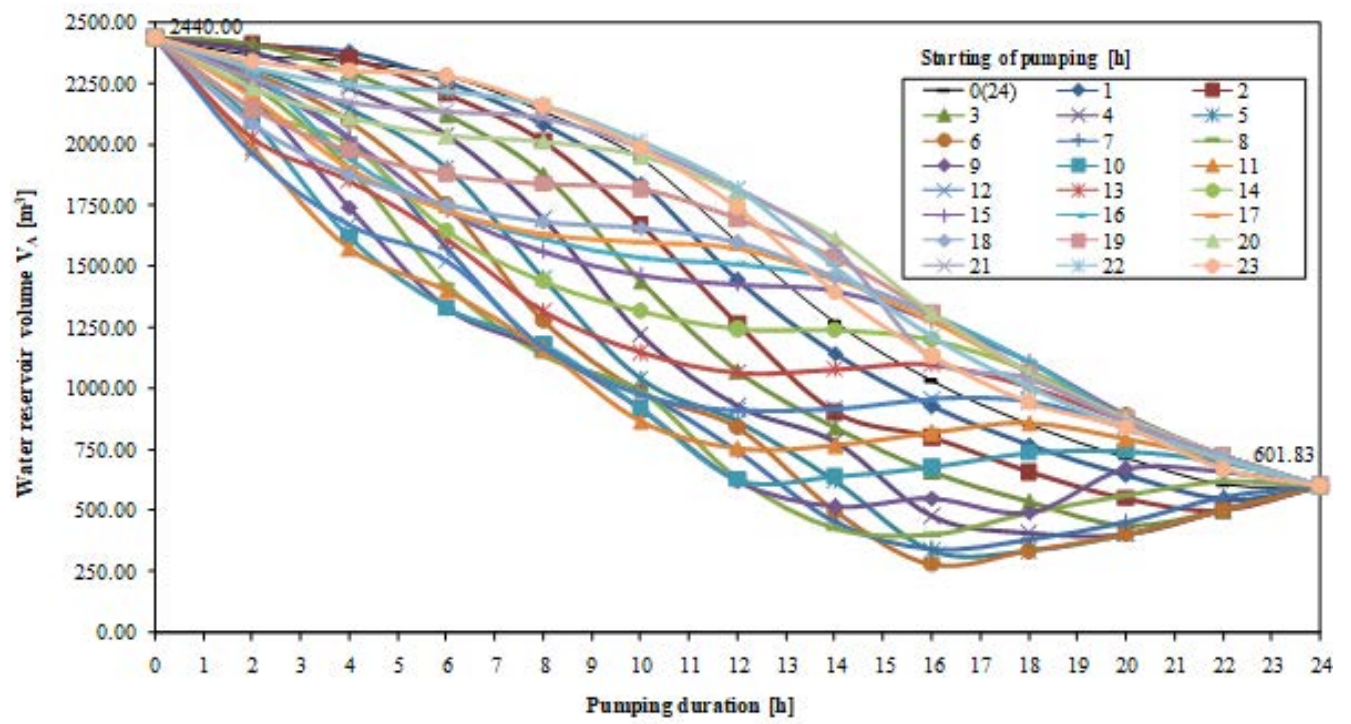

Figure 7 Changes in reservoir volume with respect to the beginning of the pumping period and different pumping durations for

of pumping, the curve is increasing, which refers to the increase in the amount of water in the reservoir. Based on the obtained results, a regularity was established that explains the relationship between the start of pumping and the extreme value - the minimum volume of the reservoir. Therefore, it can be concluded that the start time of pumping Tstart, the time at which the sum of all individual hourly water consumption $Q_{\text {out }}$,jless than the average hourly water consumption) is greater than or equal to the first individual hourly water consumption is greater than the average hourly water consumption [16]. Mathematically written, Tstart is the time $t, 1 \leq t \leq T$ for which it holds, shown in Equation 3 [18]

$$
\sum_{\substack{j=1 \\ \text { Q } \\ Q_{\text {out }, j}^{\text {hour }}}}^{t} Q_{\text {out }, j} \geq \max _{Q_{\text {out }, j} Q_{\text {aver }}^{\text {hour }}} Q_{\text {out }, j}
$$

Given the analysis of changes in the pumping regime and the impact on the volume of the reservoir is intended to show the change in the pumping regime and provide the information in which certain period of the day there is a possibility of additional water storage. Based on the above expression, obtained for the minimum volume, the start time of pumping is defined. Therefore, it is shown that it is extremely important to see how and in what way the change of the pumping regime affects the volume of 


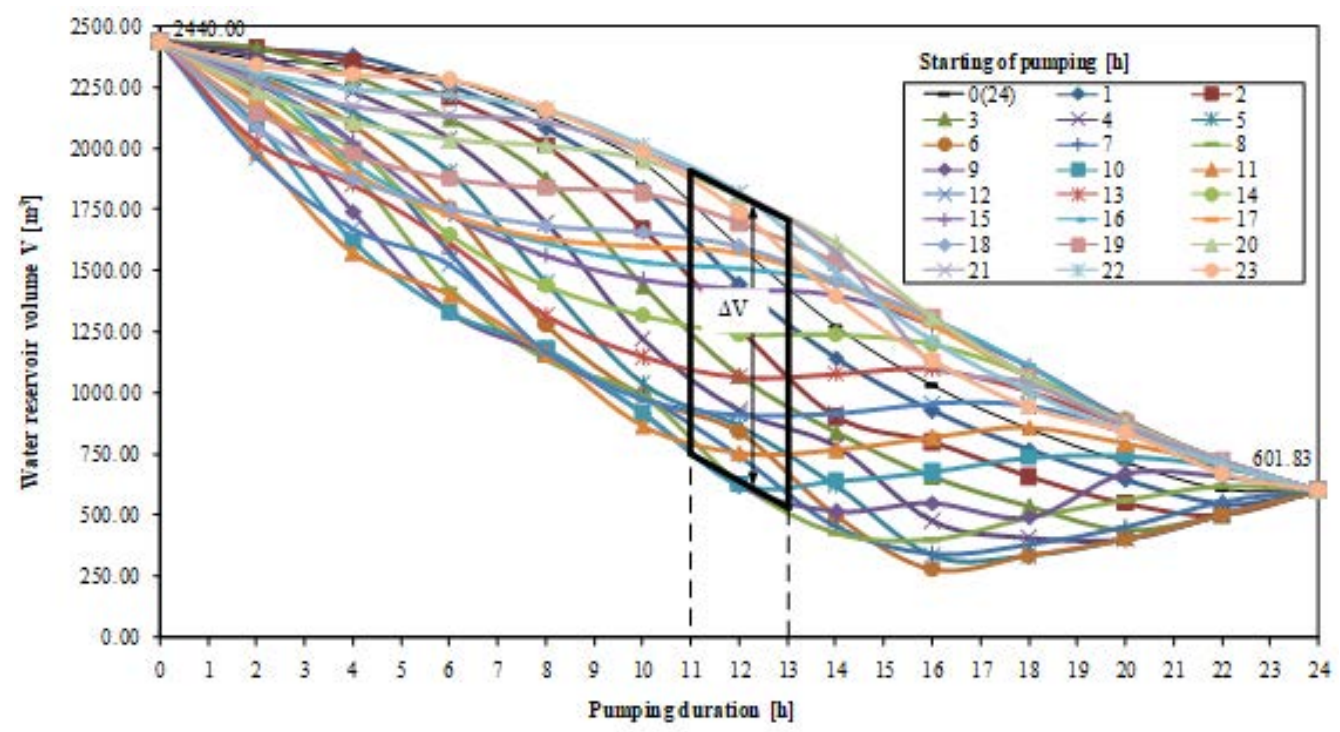

Figure 8 Dependence of the dependence of the required volume of the reservoir on the duration of pumping for the different start of pumping for $Q_{\max }^{\text {daily }}=2440 \mathrm{~m}^{3} /$ day for Variant II

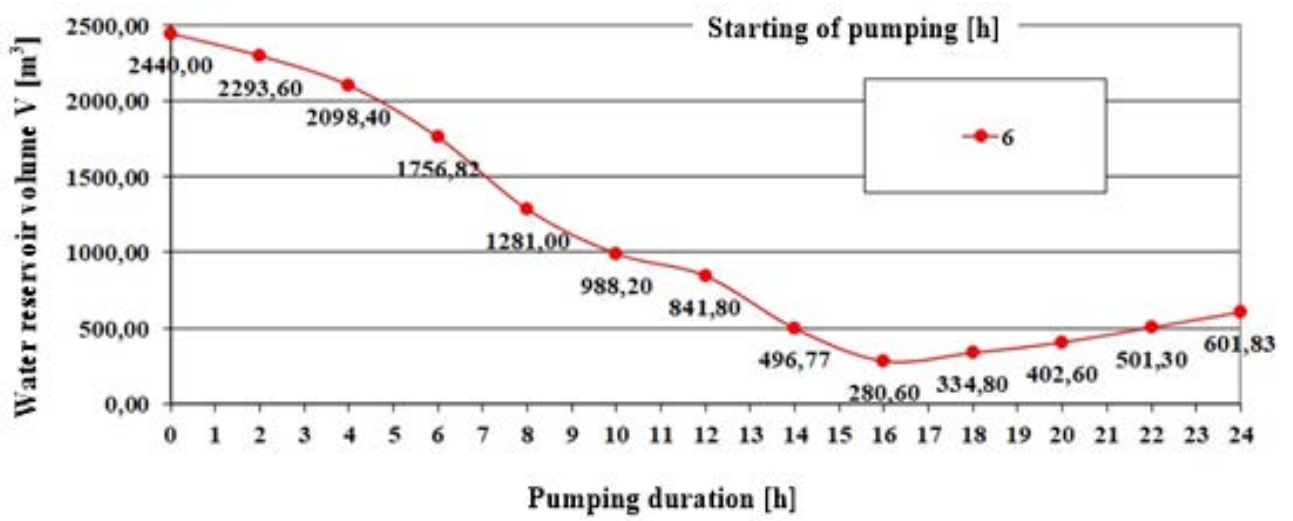

Figure 9 Dependence of the required volume of the reservoir on the pumping duration for different pumping start for $Q_{\max }^{\text {daily }}=2440 \mathrm{~m}^{3} /$ day for the extreme for pumping start at 6 AM with the corresponding pumping duration of 16 hours for Variant II

the water reservoir and to determine the possible laws or interrelations. In fact, a separate analysis of each curve in accordance with the required needs, or duration and the start of pumping, defines how you can change the volume of the reservoir.

\section{Conclusions and guidelines for further research}

The purpose of the presented analysis is to investigate, if there is an increased need for water, whether the existing water reservoir can accept a certain amount of water in a certain period, without the need for its expansion. This would lead to energy conservation, since the reservoir, in addition to the water storage, also has the role of energy storage. The conducted analysis is extremely important because it investigates how and in what way the change of pumping regime affects the volume of the reservoir. It includes possible regularities between different water consumption regimes, pumping regimes, and their influence on the size of the reservoir volume.

By defining the linear part within the diagram of the dependence of the reservoir volume, on the beginnings and durations of pumping, within the largest range between the smallest and largest reservoir volume, it is easier to find possible durations, as well as the beginnings of pumping, which significantly helps with pumping water into existing water reservoirs regarding the maximum, permitted quantities (flows) of water.

For constant pumping of water into the reservoir for 24 hours, the change in the start of pumping has no effect on the volume of the reservoir, contrary to occasional pumping. A detailed analysis of the occasional 


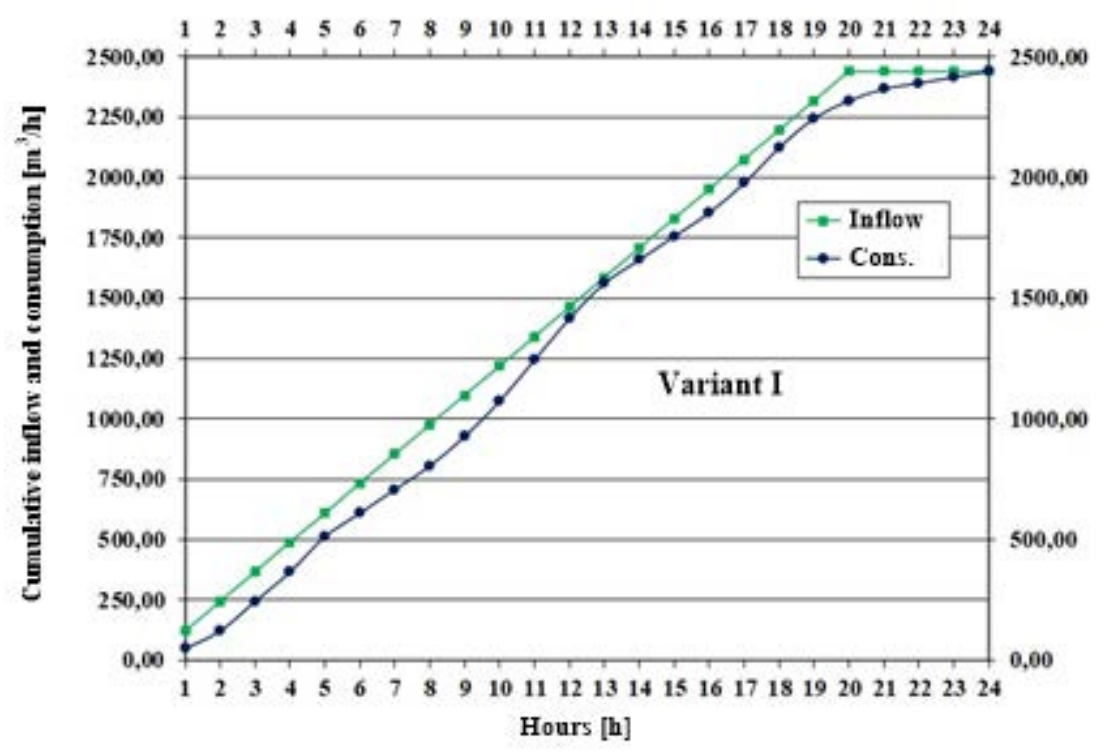

Figure 10 Display of cumulative water inflow into the water reservoir and water consumption with the start of pumping at 4 AM for Variant I

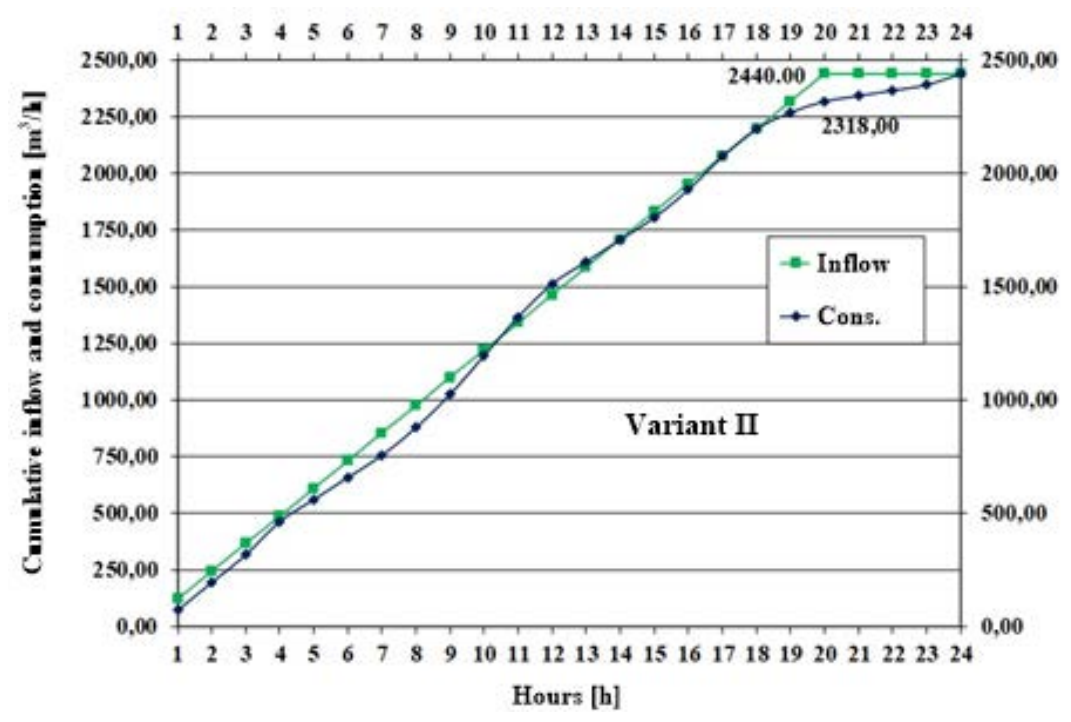

Figure 11 Display of cumulative water inflow into the water reservoir and water consumption by the population with the start of pumping at $3 \mathrm{AM}$ for Variant I

pumping regime with different beginnings and durations of pumping, unambiguously defined the time of pumping and established the law that explains the relationship between the start of pumping and the minimum volume of the reservoir (extreme). The above-mentioned leads to the conclusion that the pumping start time is the time at which the sum of all individual hourly water consumption is greater than or equal to the first individual hourly water consumption (greater than the average hourly water consumption), which also defines the start time of pumping for the case, at which for two or more different pumping starts, the largest differences between inflow and water consumption are obtained. The presented analysis also provides insight into the change of pressures in the water supply system and the possibility of regulating the pressure with respect to the minimum and maximum allowable values, which is extremely important because pressure control only by water storage avoids the installation of pressure chambers and regulation of water inlet and outlet from the reservoir. By further elaborating this research, using mathematical tools such as linear programming, dynamic programming, $0-1$ search methods, etc., it is wanted to create a "user-friendly" program (software). This means, a package in which the 


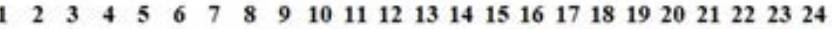

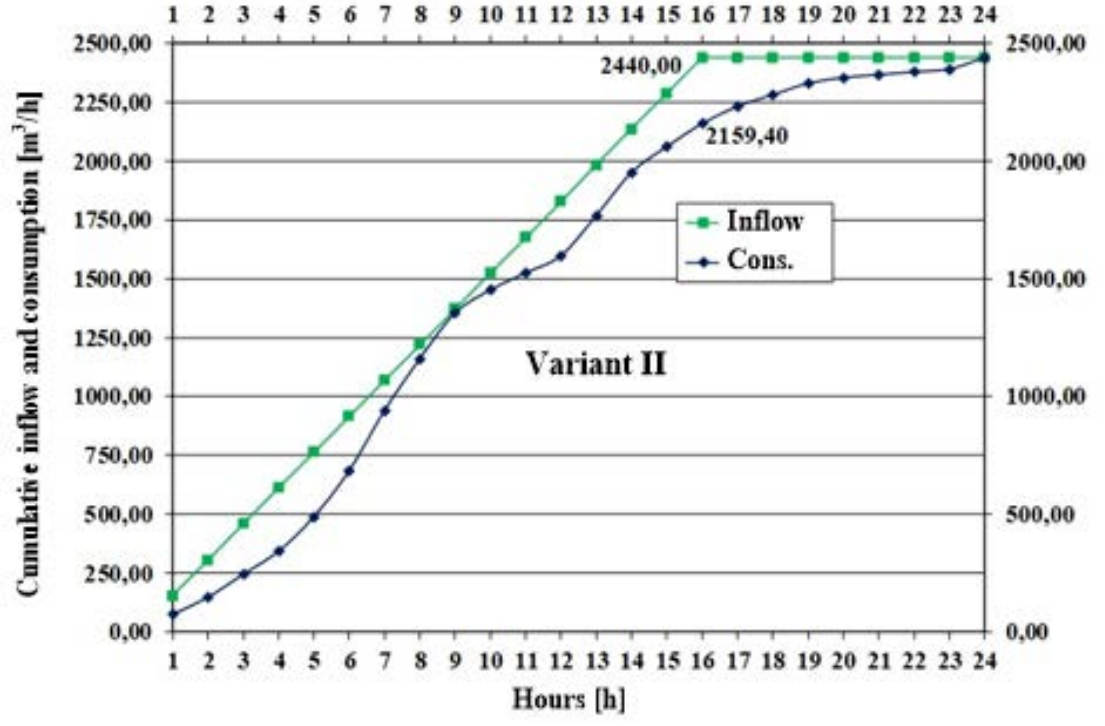

Figure 12 Display of cumulative water inflow into the water reservoir and water consumption by the population for Variant II for the start of pumping at $6 \mathrm{AM}$

data on water consumption and pumping regime would be used as input data, while the output data would represent the required size of the reservoir volume. The mentioned software has an exceptional practical value, since it would meet all the conditions for achieving autonomy in the management of the water supply system, which would greatly facilitate the work of specialized persons in the control and management sectors of UWSS due to the lack of a regulation manual.

\section{Declaration of competing interest}

We declare that we have no significant competing interests, including financial or non-financial, professional, or personal interests interfering with the full and objective presentation of the work described in this manuscript.

\section{Acknowledgments}

We are grateful to Dr. sc. Jure Margeta, Full Professor, University of Split, Faculty of Civil Engineering, Architecture and Geodesy, in Croatia on pointing out the problem, which is analyzed in this manuscript.

\section{Funding}

The author(s) received no financial support for the research, authorship, and/or publication of this article.

\section{Author contributions}

Conceptualization, Lucija Plantak and Bojan Đurin; Data curation, Lucija Plantak and Bojan Đurin; Formal analysis, Lucija Plantak; Investigation, Lucija Plantak; Methodology, Lucija Plantak and Bojan Đurin; Validation, Lucija Plantak, Bojan Đurin and Tatjana Džeba; Visualization, Lucija Plantak and Sara Dadar; Writing - original draft, Lucija Plantak, Bojan Đurin. All authors have read and agreed to the published version of the manuscript.

\section{Data Availability Statement}

The authors confirm that the data supporting the findings of this study are available within the article [and/or] its supplementary materials.

\section{References}

[1] J. Margeta and B. Đurin, "Innovative approach for achieving of sustainable urban water supply system by using of solar photovoltaic energy," Ingeniería e Investigación, vol. 37, no. 1, Jan. 01, 2017. [Online]. Available: https://revistas.unal.edu.co/index. php/ingeinv/article/view/57983

[2] J. Margeta. (2010) Planiranje, projektiranje,upravljanje, obrada vode. građevinsko-arhitektonski fakultet. Sveučilišta u Splitu. [Online]. Available: https://www.voda.hr/sites/default/files/pdf clanka/hv_76_2011_167_prikaz-knjiga.pdf

[3] B. Đurin, "Održivost rada urbanog vodoopskrbnog sustava," Ph.D thesis, University of Split, Split, Croatia, 2014. [Online]. Available: https://repozitorij.svkst.unist.hr/en/islandora/object/ gradst $\% 3 A 905$

[4] M. Abu and N. Trifunovic, "Impacts of supply duration on the design and performance of intermittent water distribution systems in the 
west bank," Water International, vol. 38, no. 3, May. 10, 2013. [Online]. Available: https://doi.org/10.1080/02508060.2013.794404

[5] M. Kim, T. Choi, M. Kim, S. Han, and J. Koo, "Optimal operation efficiency and control of water pumps in multiple water reservoir system: case study in korea," Water Supply, vol. 15, no. 1, Feb. 2015. [Online]. Available: https://doi.org/10.2166/ws.2014.079

[6] P. Bauer, R. Schneider, and C. Davidsen, "Optimizing wellfield operation in a variable power price regime," Groundwater, vol. 54, no. 1, 2016. [Online]. Available: https://doi.org/10.1111/gwat.12341

[7] H. AbdelMeguid, "Pressure, leakage and energy management in water distribution systems," M.S. thesis, Montfort University, Leicester, UK, 2011. [Online]. Available: https://dora.dmu.ac.uk/ bitstream/handle/2086/4905/PhD_Thesis.pdf?sequence=1

[8] O. Giustolisi, D. Laucelli, and L. Berardi, "Operational optimization: Water losses versus energy costs," Journal of Hydraulic Engineering, vol. 139, no. 4, Apr. 2013. [Online]. Available: https://ascelibrary. org/doi/abs/10.1061/(ASCE)HY.1943-7900.0000681

[9] G. Yu, R. S. Powell, and M. J. Sterling, "Optimized pump scheduling in water distribution systems," Journal of Optimization Theory and Applications, vol. 83, Dec. 1994. [Online]. Available: https://doi.org/10.1007/BF02207638

[10] F. Scarpa, A. Lobba, and G. Becciu, "Expeditious pump rescheduling in multisource water distribution networks," Procedia Engineering, vol. 119, 2015. [Online]. Available: https://doi.org/10.1016/j.proeng. 2015.08.938

[11] S. P. Andey and P. S. Kelkar, "Influence of intermittent and continuous modes of water supply on domestic water consumption," Water Resources Management, vol. 23, Jan. 23, 2009. [Online]. Available: https://doi.org/10.1007/s11269-008-9396-8
[12] B. Đurin, "Some aspects of the operation work of pump station and water reservoir," Periodica Polytechnica Civil Engineering, vol. 60, no. 3, Apr. 26, 2016. [Online]. Available: https://doi.org/10.3311/ PPci.7983

[13] A. B. Celeste and M. Billib, "Evaluation of stochastic reservoir operation optimization models," Advances in Water Resources, vol. 32, no. 9, Sep. 2009. [Online]. Available: https://doi.org/10.1016/ j.advwatres.2009.06.008

[14] L. S. Vamvakeridou, D. A. Savic, and G. A. Walters, "Tank simulation for the optimization of water distribution networks," Journal of Hydraulic Engineering, vol. 133, no. 6, Jun. 2007. [Online]. Available: https://doi.org/10.1061/(ASCE)0733-9429(2007)133:6(625)x

[15] J. E. V. Zyl, O. Piller, and Y. L. Gat, "Sizing municipal storage tanks based on reliability criteria," Journal of Water Resources Planning and Management, vol. 134, no. 6, Nov. 2008. [Online]. Available: https://doi.org/10.1061/(ASCE)0733-9496(2008)134:6(548)

[16] G. S. Sengar and A. S. Patil, "Optimization of water supply in urban area," International Research Journal of Engineering and Technology, vol. 7, no. 8, Aug. 2020. [Online]. Available: https://www.irjet.net/archives/V7/i8/IRJET-V718334.pdf

[17] B. Ming, P. Liu, T. Bai, R. Tang, and M. Feng, "Improving optimization efficiency for reservoir operation using a search space reduction method," Water Resources Management, vol. 31, Jan. 21, 2017. [Online]. Available: https://doi.org/10.1007/s11269-017-1569-x

[18] L. Baić, "Modeling of water pumping and consumption regime in urban water supply system," M.S. thesis, University of Zagreb, Varaždin, Croatia, 2017. [Online]. Available: https://repozitorij.gfv. unizg.hr/islandora/object/gfv:244 